\title{
Morphological parameters of blood of calves with cryptosporidiosis after applying different treatment regimens
}

\author{
Orazali Mullakaev, Ildar Zalaylov, Evgeny Kirillov, Irina Konstantinova*, and Elvira Bulatova \\ Kazan State Academy of Veterinary Medicine, Kazan 420029, Russia
}

\begin{abstract}
Recently the livestock farmers of Baltasinsky, Kukmorsky, Sabinsky, Alkeevsky and other regions of the Republic of Tatarstan have increasingly frequently faced the young cattle diseases associated with pathology of the gastrointestinal tract that have not been treated by the classical scheme of diseases with diarrhea symptoms.Sick calves had acute and subacute catarrhal gastroenteritis mainly in the later stages of which accompanied by the inflammatory process in the posterior segment of the small intestine. The manifestations of structural changes in the subepithelial lymphoid tissue of the intestine, in the stagnant digestive glands and regional lymph nodes were increased with a severity level of the clinical symptoms of the disease.In this regard, in order to obtain a complete picture of the effect of cryptosporidiosis invasion on the peripheral blood condition of sick calves, hematological studies were conducted in the dynamics of the development of the infectious process. We have studied the content of red blood cells, white blood cells including lymphocytes, granulocytes, as well as monocytes and hemoglobin on the 7th, 14th and 30th days of the experiment. Hematological studies of calves infected with spontaneous invasion of cryptosporidiosis, and after treatment, had been carried out in 2016 - 2018 at the OJSC "KukmorAgroChimService" in the Kukmorsky district of the Republic of Tatarstan in the Russian federation. Cryptosporidiosis clinically insane calves had erythropenia and leukocytopenia in the blood and low hemoglobin. Reduced oxygen capacity of the blood contributed to the development of the secondary destructive changes in the organs of hematopoietic organs. The established dynamics of a decrease in the content of eosinophilic granulocytes in the blood of calves in the first and especially in the second groups indicated a high therapeutic effect of the drugs used. Starting from the 7th day, due to the therapeutic effect of the tested medications in the places of the pathogenic effects of cryptosporidia, regenerative processes were intensified. It affected the morphological parameters of the blood.
\end{abstract}

\section{Introduction}

Cryptosporidiosis of calves is an acute or subacute ongoing invasive disease of newborn animals caused by unicellular protozoa and manifested by the digestive tract damage $[1,2]$.

Studies have shown that young calves have the highest risk of infection with the C. parvum species, and from the entire cryptosporidiosis infestation, $80 \%$ of cases of infection of animals occur in this particular species. The causative agent most often affects newborn calves and young animals under the age of 30-45 days, and less often - older animals [3, 4].

According to many authors, the causative agents of cryptosporidiosis belong to an opportunistic infection, the manifestation of which largely depends on the host's immune status and the presence of a second infection, which is why the manifestation of this invasion in some cases is mild, but there is still the potential danger of the spread of invasion [5, 6].

The fecal-oral transmission mechanism is the main way of infection of animals with cryptosporidia.
Invasion occurs in contact with infected animals and people, as well as with environmental objects. The sources of invasion are animals with cryptosporidiosis and cryptosporidiosis carriers [7, 8].

The mechanical carriers of cryptosporidia are synanthropic rodents (rats and mice) which live in livestock buildings in large numbers [9].

Violations of animal health and sanitary requirements for keeping animals predispose to infection and the further spread of cryptosporidiosis [10, 11]. Defective feeding and various infectious diseases caused by the opportunistic microflora have a significant impact on the pathogenesis of this invasion. The pathogenesis of cryptosporidiosis responds to the influence of parasites and their toxins that cause various inflammatory and immunopathological reactions in the body of sick calves [12-17].

According to R. F. Kutlimatov, in animals, there is a correlation between the level of damage of the intestinal mucosa by cryptosporidia and the severity of the disease. Moreover, in newborn animals, the entire intestine is affected, and in older animals (7-15 days old), only the posterior small intestine is affected [18].

*Corresponding author: irina.const@mail.ru 
The aim of the research is to study the morphological parameters of blood completely as recently there has been a significant spread of cryptosporidiosis invasion in calves of the neonatal period and, manifested by the clinic of the disorder of the gastrointestinal tract older in a number of livestock farms of the Republic of Tatarstan.

The research objectives included studying the blood morphology of cryptosporidiosis calves and determining the most effective scheme of using antiparasitic drugs for sick animals' treatment.

\section{Material and research methods}

Having carried out scatology of the sick calves feces at the mentioned farm and found the Cryptosporidium parvum in them, hematological and biochemical blood tests were performed. In this regard 3 groups of animals with cryptosporidiosis were formed. The first and the second groups of animals were experimental, and the third was control. Each group included 5 calves.

The sick calves of the first experimental group were injected intramuscularly with "Amoxicillin" at the rate of $1 \mathrm{ml}$ per $10 \mathrm{~kg}$ of animal body weight, the immunostimulant"Mixoferon" in the amount of 10 doses (1000000 ME) 2 times a day for 5 days and the medication "Nitamin" (CJSC "NITA PHARM") at a dose of $1 \mathrm{ml}$ once. The sick animals of the second group were used the medication "Azitronit", the immunostimulant"Mixoferon" (CJSC "Mosagrogen") in 10 doses 2 times a day for 5 days, and the the medication "Nitamin" (CJSC "NITA PHARM") at a dose of $1 \mathrm{ml}$ once.

Calves with cryptosporidiosis of the third group did not receive medical treatment.

For morphological and biochemical studies, blood sampling was performed on the 7th, 14th, 30th days upon the appointment of the test dosing schedules. Blood for hematological studies was taken from the jugular vein of calves in a volume of 4-5 $\mathrm{ml}$ using vacuum tubes and disposable syringes. The content of morphological parameters of blood cells was determined by a Medonic hematology analyzer.

\section{Results}

The results of the analysis of the hemogram of calves with cryptosporidiosis before therapy have showed an initially reduced level of erythrocytes in the blood of all animal groups. The quantitative content of erythrocytes in the blood in the control group of calves amounted averagely $3.8 \pm 0.12 \times 10^{12} / 1$, in the first experimental group $-4.1 \pm 0.25 \times 10^{12} / 1$, in the second $-4.0 \pm 0.22 \times$ $10^{12} / 1$. (table 1)

Table 1. Morphological blood parameters of calves with the use of various patterns of drug use

\begin{tabular}{|c|c|c|c|}
\hline \multirow[t]{2}{*}{ Indicator } & \multicolumn{3}{|c|}{ Group } \\
\hline & 1 (experimental) & 2 (experimental) & 3 (control) \\
\hline \multicolumn{4}{|c|}{ Before the treatment } \\
\hline Red blood cells, $10^{12} / 1$ & $4.1 \pm 0.25$ & $4.0 \pm 0.22$ & $3.8 \pm 0.12$ \\
\hline White blood cells, $10^{9} / 1$ & $13.4 \pm 0.41$ & $13.2 \pm 0.61$ & $13.6 \pm 0.46$ \\
\hline Hemoglobin, g/l & $82.3 \pm 3.71$ & $90.3 \pm 4.39$ & $83.4 \pm 3.80$ \\
\hline \multicolumn{4}{|c|}{7 th day of the treatment } \\
\hline Red blood cells, $10^{12} / 1$ & $4.9 \pm 0,09 * *$ & $5.4 \pm 0.17 * * *$ & $3.6 \pm 0.16$ \\
\hline White blood cells, $10^{9} / 1$ & $12.3 \pm 0,9$ & $11.1 \pm 0.53 * * *$ & $14.6 \pm 0.51$ \\
\hline Hemoglobin, g/l & $95.4 \pm 3.11 *$ & $101.2 \pm 2.82 * *$ & $81.0 \pm 4.64$ \\
\hline \multicolumn{4}{|c|}{$14^{\text {th }}$ day of the treatment } \\
\hline Red blood cells, $10^{12} / 1$ & $5.6 \pm 0.15^{*}$ & $7.4 \pm 0.24 * *$ & $4.1 \pm 0.19$ \\
\hline White blood cells, $10^{9} / 1$ & $9.8 \pm 0.84 *$ & $8.2 \pm 0.71 * *$ & $12.9 \pm 1.07$ \\
\hline Hemoglobin, g/l & $102.2 \pm 4.35^{*}$ & $111.4 \pm 4.42 * * *$ & $83.4 \pm 3.06$ \\
\hline \multicolumn{4}{|c|}{ 30th day of the treatment } \\
\hline Red blood cells, $10^{12} / 1$ & $6.4 \pm 0.65 * *$ & $7.1 \pm 0.11 * *$ & $4.8 \pm 0.34$ \\
\hline White blood cells, $10^{9} / 1$ & $9.7 \pm 0.63^{*}$ & $8.5 \pm 0.52 * *$ & $11.8 \pm 0.53$ \\
\hline Hemoglobin, g/l & $101.0 \pm 4.8^{*}$ & $104.6 \pm 4.84 *$ & $93.2 \pm 3.85$ \\
\hline
\end{tabular}

Note: $* \mathrm{p}<0.05, * * \mathrm{p}<0.01, * * * \mathrm{p}<0.001$

On the 7th day after the start of treating sick calves, there was an increase in the level of red blood cells in the blood of animals of all experimental groups. The number of red blood cells of calves of the first experimental group was increased by $16.3(19.5) \%$, and in animals of the second group this percentage was $18.5(35.0) \%$. In the control group, on the contrary, the level of erythrocyte levels was continued to decrease by $5.3 \%$. In digital values, the quantitative content of red blood cells in the blood of animals in the control group was averagely $3.6 \pm 0.16 \times 10^{12} / 1$, in the first experimental group of calves was $4.9 \pm 0.09 \times 10^{12} / 1$, in the second was $5.4 \pm 0.17 \times 10^{12} / 1$. These changes reflected an uneven improvement in the course of metabolic processes in the structures of the myeloid tissue of experimental calves.

14 days after the start of the experiment, a further increase in the level of erythrocytes in the blood of animals in all groups was noted. At the same time, the content of red blood cells in the blood of animals of the control group of calves was averagely $4.1 \pm 0.19 \times 10^{12} / 1$, 
while in the first experimental group it was $5.6 \pm 0.15 \mathrm{x}$ $10^{12} / 1$, in the second it increased to $7.4 \pm 0.24 \times 10^{12} / 1$.

By the 30th day of studies the calves in all groups had the level of red blood cells within the physiological norm and amounted to $4.8 \pm 0.34 \times 10^{12} / 1$ in the control group and $6.4 \pm 0.65 \times 10^{12} / 1$ in the first experimental group, and $7.1 \pm 0.11 \times 10^{12} / 1$ in the second -.

The hemoglobin level in the blood of calves before therapy was also significantly reduced. In the control group they amounted to $83.4 \pm 3.80 \mathrm{~g} / 1$, in the first experimental group $-82.3 \pm 3.71 \mathrm{~g} / \mathrm{l}$, in the second $90.3 \pm 4.39 \mathrm{~g} /$

After 7 days from the treatment start, an increase in hemoglobin content was observed in the blood of experimental calves. In the first experimental group of animals, the content of this chromoprotein was increased by $13.7 \%$, and in the second group this indicator was $10.7 \%$. In digital values, the concentration of hemoglobin in the blood in the first experimental group of calves was $95.4 \pm 3.11 \mathrm{~g} / 1$, in the second group $101.2 \pm 2.82 \mathrm{~g} / 1$. In the control group, it was noted a further decrease in the hemoglobin level to $81.0 \pm 4.64 \mathrm{~g}$ / 1. On the 14th day after the use of therapeutic agents, the hemoglobin content in the blood of calves of all experimental groups was within the physiological norm. In digital values, the hemoglobin concentration in the blood of calves of the first experimental group was averagely $102.2 \pm 4.35 \mathrm{~g} / \mathrm{l}$, of the second group -111.4 $\pm 4.42 \mathrm{~g} / \mathrm{l}$. In control animals, a slight increase in the hemoglobin level was noted, it amounted to $83.4 \pm 3.06$ $\mathrm{g} / 1$.

At the end of the experiment, 30 days after the treatment start the hemoglobin content in the blood of calves in all groups was varied within the physiological norm and amounted, averagely, to $93.2 \pm 3.85 \mathrm{~g} / 1$ in the blood of the calves of the control group, $101.0 \pm 4.8 \mathrm{~g} / 1$ in the first experimental group and it was increased to $10.6 \pm 4.84 \mathrm{~g} / 1$ in the second experimental group.

The leukocyte content in the blood of calves before the start of the experiment in all groups was higher than the physiological norm $(13.2 \pm 0.61-13.6 \pm 0.46 \times 109$ / 1).

In 7 days after the treatment start, a significant decrease in the level of leukocytes in the blood of experimental animals was observed compared with the control group $(p<0.05)$. The most significant decrease in the content of leukocytes in the blood was observed in calves of the second experimental group. In comparison with the control group of animals, this indicator was decreased by $15.9 \%$. After 14 days we noted, a further significant decrease in the leukocyte content in the blood of calves in the experimental groups, while in the blood of the calves of the control group these changes were insignificant and were averaged $12.9 \pm 1.07 \times 109 / 1$. In the first group a moderate leukocytopenia reached a value of $9.8 \pm 0.84 \times 109 / 1$, and in the second group $8.2 \pm 0.71 \times 109 / 1$.

On the 30th day of the study the level of leukocytes in the blood of experimental animals was fluctuated within the physiological norm. In digital values in the control group it amounted $11.8 \pm 0.53 \times 109 / 1$, in the first group $-9.7 \pm 0.63 \times 109 / 1$, in the second $-8.5 \pm$ $0.52 \times 109 / 1$.

Background indicators of the content of eosinophilic granulocytes in the blood of animals before the start of the experiment amounted averaged 9.4 $\pm 0.57-11.6 \pm$ $0.91 \% .7$ days after the start of treatment the content of these cells in the blood of experimental animals was decreased. In the first experimental group they were lower than the initial values by $27.5 \%$, and in the second - by $38.3 \%$. A similar tendency in of decreasing eosinophilic granulocytes in the blood was noted on the 14th day after the start of treatment.

30 days after the start of the experiment, in the blood of calves of the 1 st and 2 nd experimental groups the content of eosinophilic granulocytes was decreased and reached the physiological norm and was averaged $5.2 \pm$ $0.65 \%$ and $1.8 \pm 0.42 \%$, respectively.

The calves of the third control group had the eosinophil content in the blood higher than physiological norms throughout the entire period of the studies and it was ranged from $7.8 \pm 0.55$ to $10.0 \pm 1.12 \%$ caused by the destructive processes in the inflamed gastrointestinal tract (table 2).

Prior to the use of therapeutic agents, the blood of animals in all groups had neutrophilic leukocytosis with a nuclear shift to the left. Background indicators of the stab neutrophilic granulocytes in the blood composition of calves were ranged from $21.4 \pm 0.91$ to $23.2 \pm 1.92 \%$. In 7 days after the treatment start there was a decrease in the number of stab neutrophilic leukocytes in all experimental groups. In the first group of calves the content of neutrophilic granulocytes was lower than the initial values by $10.1 \%$, in the second $-32.7 \%$. In 14 days, the content of neutrophilic granulocytes in the blood of calves of the experimental groups was $14.8 \pm$ $0.82 \%$ and $9.4 \pm 1.04 \%$, respectively. At the end of the experiment the content of neutrophilic granulocytes in all experimental groups were decreased significantly and their indices were ranged from $4.6 \pm 0.91-8.6 \pm 0.76 \%$.

The indicators of the content of segmented neutrophils in the blood of calves before the start of the experiment were ranged from $13.4 \pm 1.82 \%$ to $15.2 \pm$ $1.14 \%$. In digital values, in 7 days after using medications in all groups, the content of segmented neutrophilic granulocytes was slightly higher than the initial values $(16.0 \pm 1.2 \%, 18.4 \pm 0.84 \%, 18.4 \pm 0.82 \%$ respectively). Until the end of the experiment, their number in the experimental groups was ranged from $19.6 \pm 1.64$ to $25.8 \pm 0.74 \%$.

The content of lymphocytes in the blood of sick animals of all groups before treatment was ranged from $46.2 \pm 0.96-48.4 \pm 1.0 \%$. On the 7 th day after the treatment start in the first experimental group there was noted an increase in the number of lymphocytes by $3.7 \%$, in the second - by $10.7 \%$. In the subsequent periods of observation their content in the blood of animals of the experimental groups remained within the physiological norm. In the control group of calves of the experiment, the blood lymphocyte count decreased to $44.8 \pm 1.39 \%$ on the 7 th day, it was $44.4 \pm 2.2 \%$ on the 14 th day, by the end of the experiment the lymphocyte count reached $55.4 \pm 1.2 \%$. 
Table 2. Leukogram of the calves after applying various methods of treatment

\begin{tabular}{|c|c|c|c|c|c|c|}
\hline $\begin{array}{l}\text { Subgro } \\
\text { up, No. }\end{array}$ & $\begin{array}{c}\text { Basophilic } \\
\text { leukocytes, } \\
\%\end{array}$ & $\begin{array}{c}\text { Eosinophilic } \\
\text { granulocytes, \% }\end{array}$ & $\begin{array}{l}\text { Stab neutrophilic } \\
\text { granulocytes, \% }\end{array}$ & $\begin{array}{c}\text { Segmented } \\
\text { neutrophilic } \\
\text { granulocytes, } \\
\%\end{array}$ & $\begin{array}{c}\text { Lymphocytes, } \\
\%\end{array}$ & $\begin{array}{c}\text { Monocyt } \\
\text { es, } \%\end{array}$ \\
\hline \multicolumn{7}{|c|}{ Before the treatment } \\
\hline 1. & 0 & $11.6 \pm 0.91$ & $21.6 \pm 1.5$ & $14.4 \pm 1.35$ & $46.2 \pm 0.96$ & $6.2 \pm 0.82$ \\
\hline 2. & 0 & $9.4 \pm 0.57$ & $23.2 \pm 1.92$ & $13.4 \pm 1.82$ & $48.4 \pm 1.0$ & $5.0 \pm 0.61$ \\
\hline 3. & 0 & $10.0 \pm 1.12$ & $21.4 \pm 0.91$ & $15.2 \pm 1.14$ & $47.6 \pm 1.68$ & $5.8 \pm 0.42$ \\
\hline \multicolumn{7}{|c|}{7 th day of the treatment } \\
\hline 1. & 0 & $8.4 \pm 0.76$ & $19.4 \pm 1.35^{* *}$ & $18.4 \pm 0.84$ & $48.0 \pm 1.17 * *$ & $5.8 \pm 0.42$ \\
\hline 2. & 0 & $5.8 \pm 0.22 * *$ & $15.6 \pm 0.91 * * *$ & $18.4 \pm 0.82$ & $54.2 \pm 1.14 * * *$ & $6.0 \pm 0.61$ \\
\hline 3. & 0 & $8.6 \pm 0.57$ & $25.6 \pm 1.04$ & $16.0 \pm 1.2$ & $44.8 \pm 1.39$ & $5.2 \pm 0.55$ \\
\hline \multicolumn{7}{|c|}{ 14th day of the treatment } \\
\hline 1. & 0 & $7,6 \pm 0,57^{*}$ & $14.8 \pm 0.82$ & $19.6 \pm 1.64$ & $52.6 \pm 2.08 *$ & $5.2 \pm 0.55$ \\
\hline 2 & 0 & $3,0 \pm 0,5 * * *$ & $9.4 \pm 1.04 * * *$ & $23.2 \pm 0.65^{* *}$ & $60.4 \pm 1.04 * * *$ & $4.2 \pm 0.42$ \\
\hline 3 & 0 & $9,8 \pm 0,42$ & $20.8 \pm 1.78$ & $18.2 \pm 0.57$ & $44.4 \pm 2.2$ & $5.4 \pm 0.57$ \\
\hline \multicolumn{7}{|c|}{ 30th day of the treatment } \\
\hline 1. & 0 & $5.2 \pm 0.65^{*}$ & $8.6 \pm 0.76$ & $24.8 \pm 2.1 * * *$ & $58.2 \pm 1.64 *$ & $3.4 \pm 0.57$ \\
\hline 2. & 0 & $1.8 \pm 0.42 * * *$ & $4.6 \pm 0.91 * *$ & $25.8 \pm 0.74 * * *$ & $65.2 \pm 0.55 * * *$ & $2.6 \pm 0.45$ \\
\hline 3. & 0 & $7.8 \pm 0.55$ & $10.2 \pm 1.29$ & $23.0 \pm 1.0$ & $55.4 \pm 1.2$ & $3.8 \pm 0.42$ \\
\hline
\end{tabular}

The monocyte content in the blood of calves of all groups before the experiment was ranged from $5.0 \pm$ $0.61-6.2 \pm 0.82 \%$. On the 7 th day after the treatment start a decrease in the content of these cells by $6.4 \%$ was noted in the first experimental group, in the second experimental group the blood macrophages were more than the initial values - by $16.6 \%$. On the 14 th day, a marked decrease in the monocyte content was observed in the blood of animals of the experimental groups, it continued until the end of the experiment. In the control group of animals, the indicators of the number of monocytes in the blood of calves were ranged from $3.8 \pm$ 0.42 to $5.8 \pm 0.42 \%$.

\section{Conclusion}

Hematological studies have established that before treatment all calves with cryptosporidiosis had a reduced level of red blood cells, hemoglobin and absolute leukocytosis.

After the therapy, it was noted that the calves of the experimental groups had a steady tendency to increase the red blood cells, hemoglobin, as well as a decrease in the content of leukocytes with maximum severity by the end of the month observation. We noted that calves with cryptosporidiosis, as a result of prolonged damage to the mucous membrane of the gastrointestinal tract, had eosinophilic and neutrophilic granulocytosis, and moderate monocytosis.

Having carried out the therapy for the sick calves in the experimental groups, a sharp improvement in the clinical condition was noted. The maximum effectiveness of the treatment was observed in the calves of the second experimental group where the medication "Azitronit" was used in combination with "Mixoferon".

\section{References}

1. S. Sh. Abdulmagomedov, V. F. Nikitin, Russian Parasitol. J. 2, 22-23 (2014)

2. S. Sh. Abdulmagomedov, R. A. Nuratinov, R. M. Bakrieva, A. Yu. Aliev, Sci. notes of the KSAVM 217, 3-7 (2014)

3. S. Masood, A. Maqbool, U. J. Khan et al., J. Zool. 45(4), 935-940 (2013)

4. E.J. Brook, R.M. Christley, N.P. French, C.A. Hart, Lett. Appl. Microbiol. 46, 26-31 (2008)

5. V. V. Makarov, Veterinary pathology 1, 7-17 (2008)

6. V. N. Sukhomlinov, O. A. Manzhurina, B. V. Romashov, Theory and practice of parasitic diseases of animals 15, 298 (2014)

7. B.D. Jarvie, L.A. Trotz-Williams, D.R. McKnight et. al., J. Dairy Sci. 88, 1801-1806 (2005)

8. L. Robertson, B. Gjerde, T. Forberg et al., Scand. J. Infect Dis. 23(9), 810-813 (2006)

9. V. F. Nikitin, Veterinary science 9, 32-33 (2004)

10. V.A. Vasilieva, P.A. Kulyasov, Yu.E. Kurochkina, Fundamental research 6, 942-945 (2014)

11. E.G. Kirillov, D.G. Latypov, I.N. Zalyalov et al., Sci. notes of the KSAVM 225, 39-42 (2016)

12. I.N. Zalyalov, E.G. Kirillov, E.A. Zaikina, Morphology 153, 112 (2018)

13. E. Budu-Amoako, S.J. Greenwood, B.R. Dixon, Vet Parasitol. 184, 1-9 (2012)

14. P. Klein, T. Kleinova, Z. Volek, J. Simunek, Vet Parasitol. 152, 53-59 (2008)

15. A. Muhid, I. Ng. J. Robertson, U. Ryan, ExpParasitol. 127, 534-538 (2011) 
16. M. Shahiduzzaman, A. Daugschies Vet Parasitol. 188, 203-214 (2012)

17. C. Silverlas, K. de Verdier, U. Emanuelson et al., Parasitol Res. 107, 435-444 (2010)
18. R. F. Kutlimanov, E. N. Skovorodin, Morphology 9 , 174-175 (2010) 